\title{
What impact does maths anxiety have on university students?
}

\author{
Eihab Khasawneh ${ }^{1,2^{*}}$, Cameron Gosling ${ }^{1}$ and Brett Williams ${ }^{1}$
}

\begin{abstract}
Introduction: Maths anxiety is defined as a feeling of tension and apprehension that interferes with maths performance ability, the manipulation of numbers and the solving of mathematical problems in a wide variety of ordinary life and academic situations. Our aim was to identify the facilitators and barriers of maths anxiety in university students.

Method: A scoping review methodology was used in this study. A search of databases including: Cumulative Index of Nursing and Allied Health Literature, Embase, Scopus, PsycInfo, Medline, Education Resources Information Centre, Google Scholar and grey literature. Articles were included if they addressed the maths anxiety concept, identified barriers and facilitators of maths anxiety, had a study population comprised of university students and were in Arabic or English languages.

Results and discussion: After duplicate removal and applying the inclusion criteria, 10 articles were included in this study. Maths anxiety is an issue that effects many disciplines across multiple countries and sectors. The following themes emerged from the included papers: gender, self-awareness, numerical ability, and learning difficulty. The pattern in which gender impacts maths anxiety differs across countries and disciplines. There was a significant positive relationship between students' maths self-efficacy and maths performance and between maths self-efficacy, drug calculation self-efficacy and drug calculation performance.

Conclusion: Maths anxiety is an issue that effects many disciplines across multiple countries and sectors. Developing anxiety toward maths might be affected by gender; females are more prone to maths anxiety than males. Maths confidence, maths values and self-efficacy are related to self-awareness. Improving these concepts could end up with overcoming maths anxiety and improving performance.
\end{abstract}

Keywords: Anxiety, Mathematics anxiety, Barriers, Facilitators, And gender

\section{Introduction}

Maths anxiety can be defined as a feeling of tension, apprehension and anxiety that interferes with maths performance ability the manipulation of numbers and the solving of mathematical problems in a wide variety of ordinary life and academic situations [1]. According to

\footnotetext{
*Correspondence: eihab.khasawneh@monash.edu; eakhasawneh1@just.edu. jo

${ }^{1}$ Department of Community Emergency Health and Paramedic Practice, Monash University, Monash University-Peninsula Campus, McMahons Road, Frankston, VIC, Australia

Full list of author information is available at the end of the article
}

Olango [2] maths anxiety consists of an affective, behavioural and cognitive response to a perceived threat to self-esteem that occurs as a response to situations involving mathematics. Maths anxiety, which is rooted in emotional factors, can be differentiated from dyscalculia, which is characterized by a specific cognitive deficit in mathematics [3], in two ways. Firstly, maths anxiety can exist in people who have maths capability even though they may dislike maths. Secondly, maths anxiety has an emotional component which is not the case in dyscalculia [4]. 
Maths anxiety may occur in all levels of education from primary school to university education. Harari et al. [5] reported that negative reactions and numerical confidence are the most salient dimensions of maths anxiety in a sample of first-grade students. Similar findings were also observed at tertiary levels across multiple disciplines, including health care professions. For example, Roykenes and Larsen [6] studied 116 baccalaureate nursing students and found that there was a negative relationship between previous mathematic likes/dislikes and self-assessment of mathematic ability.

Many factors may contribute to or facilitate the maths anxiety. These factors or facilitators may include teachers, parents, peers and society. Negative experiences of maths learning in classroom or home can lead to maths anxiety [7]. Firstly, the teacher plays important role in making the class more attractive and reducing anxieties. Good maths teachers can create a learning environment in which students have a positive expectation about their learning [8]. Secondly, parents play an important part in developing or reducing the maths anxiety of their children. Parents' behaviours and relations with children are very important in this aspect [7]. By discussing the anxieties and the fears that their children might face, the parents are able to pinpoint any learning problem at early stage [8]. This might prevent the developing of any learning anxieties that the students might face later in life. Moreover, parents' maths anxiety causes their children to learn less maths over the school year and to have more maths anxiety by the school year's end [9]. Thirdly, peers play important role in facilitating maths anxiety [7]. Peers at any stage of learning may have a negative impact on their colleagues, for example when students might feel inferior in front of their colleagues when they make mistakes [7]. Finally, society can contribute to the development of maths anxiety due to the misconception about mathematics, or maths myths [7].

Maths anxiety has negative impacts on individuals; many students who suffer from mathematics anxiety have little confidence in their ability to do mathematics and tend to take the minimum number of required mathematics courses, which greatly limits their career [10]. Fortunately, certain strategies can act as barriers, or prevent maths anxiety occurring. Uusimaki and Kidman [11] stated that whenever the persons become self-aware of maths anxiety and its consequences, their abilities to overcome it might increase [11]. On the other hand, activity-based learning and online/distance learning may reduce the fear of looking stupid in front of peers [12]. Another strategy is the use of untimed/unassessed (low stakes) tests to reduce the maths anxiety as well as to increase confidence [13]. Relevancy of studying maths can reduce maths anxiety; applying mathematics and statistics to real-life examples rather than pure maths can reduce maths anxiety [13].

Empirical investigations first began on maths anxiety in the 1950s, and Dreger and Alken [14] introduced the concept of maths anxiety to describe students' attitudinal difficulty with maths. The aim of this study was to identify the facilitators and barriers of maths anxiety in university students using a scoping review methodology.

\section{Method}

A scoping review methodology was used in conducting this study to allow for a greater breadth of literature to be investigated. Scoping reviews identify and map existing literature on a selected subject. This scoping review utilised the Arksey and O'Malley framework which includes six methodological steps: identifying the research question, identifying relevant studies, selecting studies, charting the data, collating, summarising and reporting the results and consulting experts [15]. The scoping approach systematically maps and reviews existing literature on a selected topic [16] including evidence from both peerreviewed research and the non-peer reviewed literature.

\section{Identify the research question}

After several review iterations, the research team agreed on the question that guided this review: What are the barriers and facilitators of maths anxiety in university students? This question was broad so it could cover a wide literature in different disciplines that allowed a better summary of the available literature.

\section{Identify relevant studies}

A list of search terms was compiled from the available literature and previous research into maths anxiety and students. Suitable Medical Subject Headings (MeSH) terms and free text keywords were identified (Table 1). A search of databases included: Cumulative Index of Nursing and

Table 1 Search strategy including the Medical Subject Heading (MeSH) and the keywords

\begin{tabular}{|c|c|c|c|c|}
\hline $\begin{array}{l}\text { MeSH } \\
\text { University students }\end{array}$ & $\begin{array}{l}\text { MeSH } \\
\text { Barriers }\end{array}$ & $\begin{array}{l}\text { MeSH } \\
\text { Facilitators }\end{array}$ & $\begin{array}{l}\text { MeSH } \\
\text { Maths anxiety }\end{array}$ & \\
\hline $\begin{array}{l}\text { Keyword } \\
\text { University students }\end{array}$ & $\begin{array}{l}\text { Keyword } \\
\text { Obstacle* inhibitor }{ }^{*} \text {, limit*, } \\
\text { blockage*, barricade* }^{*} \\
\text { impedimen*, drawback* }^{*}\end{array}$ & $\begin{array}{l}\text { Keyword } \\
\text { Develop*, promote* }{ }^{*} \text { arrange*, } \\
\text { aid }^{*} \text {, support*, reinforce*, } \\
\text { contribute* }^{*}\end{array}$ & $\begin{array}{l}\text { Keyword } \\
\text { Mathematics, mathematical } \\
\text { concepts }\end{array}$ & $\begin{array}{l}\text { Keyword } \\
\text { Apprehend*, concern*, panic*, } \\
\text { psychologic stress*, prob- } \\
\text { lem*, phobia*, fear*, stress* }\end{array}$ \\
\hline
\end{tabular}


Allied Health Literature (CINHAL), Embase, Scopus, PsycInfo, Medline, ERIC, Trove, Google Scholar and Grey literature. The search involved any related studies from July-2018 backward. Studies in Arabic and English languages were filtered from the search yield and the abstracts scanned. The databases search were conducted by one of the researchers (EK). The search yield resulted in 656 records which were exported to EndNote17 referencing for screening.

Duplicates and irrelevant studies were removed by one of the researchers (EK) and potentially relevant abstracts were complied. The selection process was conducted at two levels: a title and abstract review and full-text review. The title and abstract of the retrieved studies were independently screened (EK and BW) for inclusion based on predetermined criteria. In the second stage, the selected studies full text of potentially eligible studies were assessed and inclusion confirmed by two of the authors (EK and BW). After removing the duplicates, (EK and BW) conducted the title and abstract review of 656 articles. After applying the inclusion criteria 20 articles resulted. These 20 articles were reviewed by (EK and $\mathrm{BW}$ ) for the second time which ended in 10 articles to be involved in the scoping review.

\section{Study selection (Fig. 1)}

Articles that met the following inclusion criteria were selected.

1. Research articles (of any design) available in full text.

2. The article addressed the maths anxiety concept.

3. The article identified the barriers and the facilitators of maths anxiety.

4. The article had a study population comprised of university students.

5. The article was in Arabic or English languages.

Articles that are systematic and scoping reviews, abstracts, editorials and letters for editors were excluded.

\section{Charting the data}

This stage allows data extraction from the included studies for more data description. A narrative review method was used to extract the data from each study. Narrative reviews summarise studies from which conclusions can be drawn into more holistic interpretation by the reviewers [17]. The data included: the author and the year of publication, the country the study was conducted in, the study design or type, the sample size, results and the theme emerges from the study (Table 2). Four themes emerged following full-text review of the 10 included papers, these included: gender, self-awareness, numerical ability and learning difficulties.

\section{Collating, summarising and reporting the results}

The data extracted from the included studies are reported in Table 2. The table shows a summary of the selected articles in this scoping review study. It presents data on the different scales used to evaluate the maths anxiety across the different disciplines. Key outcome data from each of the included studies is presented and includes some of the causes or predictors of maths anxiety in university students such as gender and self-efficacy.

\section{Consultation (optional)}

Two experts were contacted for consultation to ensure no new or existing literature was missed; however no new articles were added following this consultation.

\section{Discussion}

Maths anxiety is an issue that effects many disciplines across multiple countries and sectors. Literature analysed in this scoping review spanned disciplines as diverse as education, engineering, health and science while covering diverse geographical locations such as United States (US), Austria, United Kingdom (UK), Israel, Portugal and Canada. The included articles utilised an array of varied study designs, including, cross-sectional, randomised control trial, and prospective cohort studies. The main themes that emerged from this review include gender, self-awareness, numerical ability, and learning difficulty each of these will now be synthesised and discussed.

\section{Gender}

Six articles addressed the gender concept; two American studies, three European and one Israeli study with mixed findings for the role gender plays in maths anxiety. Some of these articles found that gender has a role in maths anxiety $[18,18,20,21]$, while others found there was no significant difference between males and females [20, 22]. For example, a study of female psychology students in the US reported more maths anxiety than males [19] whereas there was no significant difference between males and females in maths anxiety in psychology students reported in the UK [20]. Psychology female students in the US [19] and Austria [21], and social science and education female students in Israel showed more maths anxiety than male students [22]. While in another study there was no significant difference in maths anxiety between males and females in the Portuguese engineering students [23].

The reasons why females frequently report higher maths anxiety than males is not well understood [24]. One explanation might be the different gender socialisation during childhood may differentially affect the anxiety experienced by males and females in certain situations which is known as the sex-role socialization 


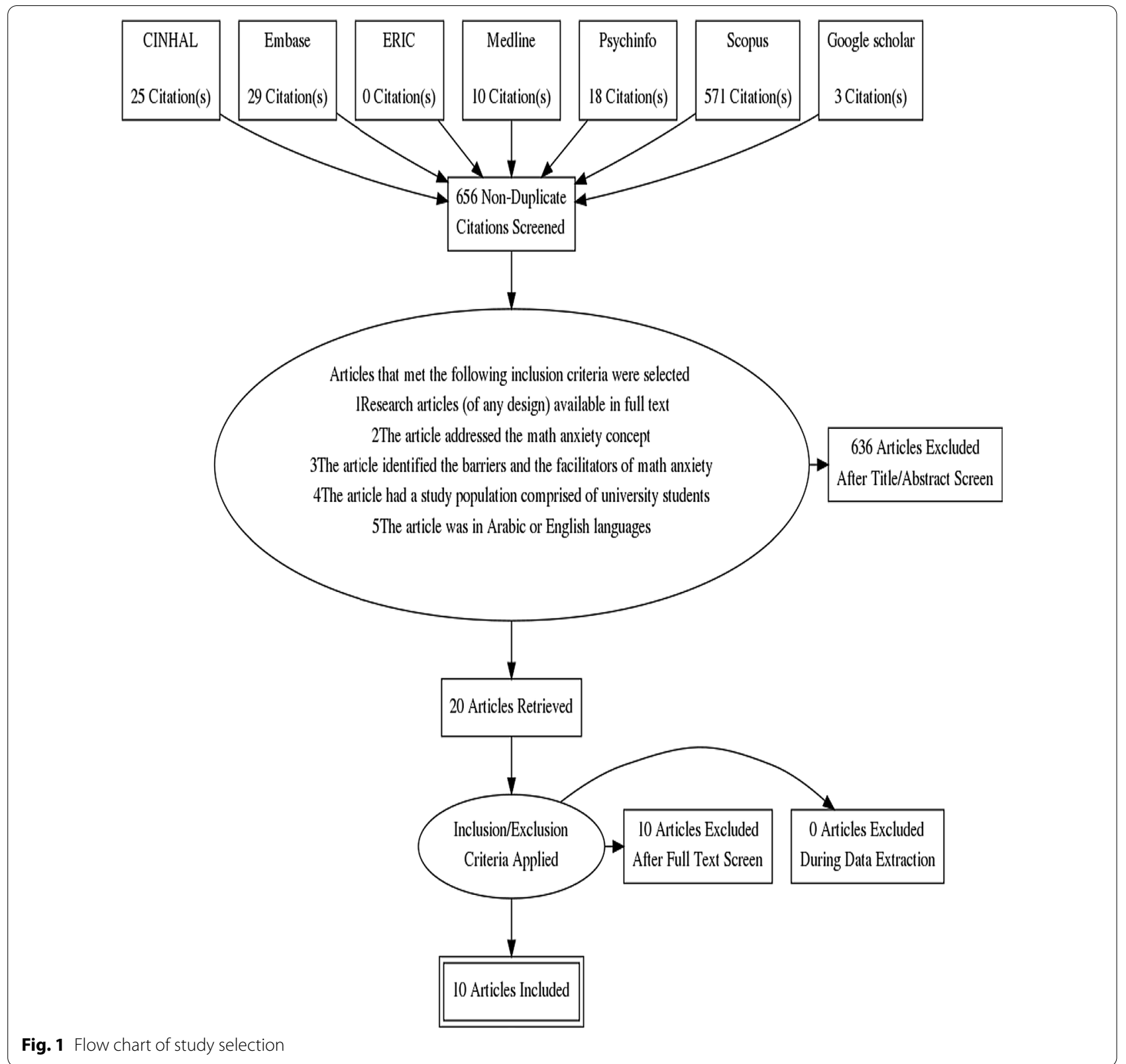

hypothesis [24]. The sex-role socialization hypothesis argues that because mathematics has been traditionally viewed as a male domain, females may be socialised to think of themselves as mathematically incompetent and therefore females may avoid mathematics. When females do participate in mathematical activities they may experience more anxiety than males [24].

The pattern of gender effect on maths anxiety is different among disciplines and countries. In a recent study, Paechter et al. [21] administered the Revised Maths Anxiety Ratings Scale (R-MARS) to 225 psychology students at the University of Graz, Austria. This study showed that there were three antecedents of maths anxiety. Firstly, female gender who reported a higher level of maths anxiety $\beta=-0.660$. Secondly, a high proneness to experience anxiety in general report higher levels of maths anxiety $\beta=0.385$. Finally, poor grades in maths. According to Paechter et al. [21] maths anxiety is inversely related to maths grades $\beta=0.393$. Of the above three factors, female gender was the most strongly related to maths anxiety and is supported by the findings of other studies such as Devine et al. [23]. Developing anxiety toward maths might be effected by gender and highlights a specific area for future empirical work. 
Table 2 Included studies reporting author and year of publication, country of origin, undergraduate discipline, study design and participant numbers, primary outcomes and scoping review theme(s)

\begin{tabular}{|c|c|c|c|c|c|}
\hline References & Country & Discipline & Design and participants & Outcomes & Theme \\
\hline Zeidner [22] & Israel & $\begin{array}{l}\text { Social science and education } \\
\text { students who had undertaken } \\
\text { a statistics unit }\end{array}$ & $\begin{array}{l}\text { Cross sectional } \\
n=431\end{array}$ & $\begin{array}{l}\text { Lack of maths foundation and } \\
\text { low maths self-esteem rein- } \\
\text { force maths anxiety } \\
\text { Females have higher statis- } \\
\text { tics test anxiety than males } \\
(59.33>54.28, \mathrm{t}(429)=-3.29 \text {, } \\
p<0.001) \\
\text { Statistics anxiety is correlated } \\
\text { positively with maths anxiety } \\
\text { experienced in high school( } r \\
(265)=0.410, p<0.05\end{array}$ & Self-awareness \\
\hline Hopko et al. [19] & USA & Psychology & $\begin{array}{l}\text { Randomised controlled trial } \\
n=64\end{array}$ & $\begin{array}{l}\text { High maths anxious individuals } \\
\text { generally exhibited higher } \\
\text { error rates on mathematical } \\
\text { tasks especially those requiring } \\
\text { working memory resources } \\
\text { MARS-R mean score }=59.0 \text {. } \\
\text { Females reported more } \\
\text { maths anxiety than males ( } t \\
(812)=5.53, p<0.001 \text { ) }\end{array}$ & Gender \\
\hline Maloney et al. [28] & Canada & Not reported & $\begin{array}{l}\text { Cross sectional } \\
n=48\end{array}$ & $\begin{array}{l}\text { High Maths Anxious (HMA) } \\
\text { individuals have less precise } \\
\text { representations of numerical } \\
\text { magnitude than their Low } \\
\text { Maths Anxious (LMA) peers } \\
\text { t test on the slopes of the dis- } \\
\text { tance effects for HMA and LMA } \\
\text { by revealing a steeper numeri- } \\
\text { cal distance effect for HMA } \\
\text { than for LMA group }(46)=2.0 \text {, } \\
p=0.05\end{array}$ & Gender \\
\hline
\end{tabular}

McMullan et al. (26) UK Nursing Cross sectional $n=229$
Hunt et al. (20) UK Psychology Cross sectional
Strong significant relationship between maths anxiety, selfefficacy and ability in nursing students

93\% of the Students who failed the numeracy test and $83 \%$ of those who failed the drug calculation test demonstrated signs of maths anxiety (score $>25 \%$ )

Students who failed numeracy test were significantly more anxious $(t(216)=7.04$ $p<0.001$ and less confident $(t(214)=-5.77, p<.001)$ in performing numerical calculations and less confident in performing drug calculation ( $t$ (213) $=-3.42, p=0.001)$

There is a significant positive cor- Self-awareness relation between maths anxiety and fixations, dwell time, and saccades. No significant difference between males and females on self-reported maths anxiety $r(67)=0.13, p=0.26$. Overall sample mean for maths anxiety $48.42, \mathrm{SD}=13.97$ 
Table 2 (continued)

\begin{tabular}{|c|c|c|c|c|c|}
\hline References & Country & Discipline & Design and participants & Outcomes & Theme \\
\hline Jordan et al. [30] & UK & Psychology, nursing and other & $\begin{array}{l}\text { Prospective cohort } \\
\text { Dyslexia group } n=28 \\
\text { Control group } n=71\end{array}$ & $\begin{array}{l}\text { Higher maths anxiety was associ- } \\
\text { ated with having a dyslexia } \\
\text { diagnosis } \\
\text { The predictors of maths } \\
\text { anxiety: self-esteem }(r=-327 \text {, } \\
p=0.001) \text {, worrying }(r=.394 ; \\
p<.001) \text {, denial }(r=.238 \\
p=0.018) \text {, seeking instru- } \\
\text { mental support }(r=.206 ; \\
p=0.040) \text { and positive } \\
\text { reinterpretation }(r=-.216 ; \\
p=0.032)\end{array}$ & Numerical ability \\
\hline Liew et al. [18] & USA & Not reported & $\begin{array}{l}\text { Cross sectional } \\
n=184\end{array}$ & $\begin{array}{l}\text { Interventions targeting emotion } \\
\text { regulation and stress manage- } \\
\text { ment skills may help individu- } \\
\text { als to reduce their maths and } \\
\text { test anxieties } \\
\text { Coefficient of gender on } \\
\text { avoidance temperament was } \\
\text { significant, higher in females } \\
(M=0.17, S D=0.80) \text { than in } \\
\text { males }(M=-0.41, S D=0.84)\end{array}$ & Gender \\
\hline Hendy et al. (27) & USA & Mathematics & $\begin{array}{l}\text { Cross sectional } \\
n=368\end{array}$ & $\begin{array}{l}\text { Students with low Maths confi- } \\
\text { dence or high maths anxiety } \\
\text { might benefit from the maths } \\
\text { self-evaluation and self-regula- } \\
\text { tion intervention that is guided } \\
\text { by Ramdass and Zimmerman } \\
2008 \text { suggestions } \\
\text { The scales related to maths belief } \\
\text { that are used in this study: } \\
\text { Maths Value Scale (MVS), Maths } \\
\text { Confidence Scale (MCS) and } \\
\text { Maths Barriers Scale (MBS) } \\
\text { The most commonly reported } \\
\text { maths belief was Maths Con- } \\
\text { fidence (mean rating = 3.79, } \\
\text { SD }=0.90\end{array}$ & Learning difficulty \\
\hline Alves [23] & Portugal & Engineering & $\begin{array}{l}\text { Cross sectional } \\
n=140\end{array}$ & $\begin{array}{l}\text { Gender shows no differences } \\
\text { in the perceived impor- } \\
\text { tance of maths anxiety. The } \\
\text { Mann-Whitney test showed } \\
\text { no significant differences in } \\
\text { anxiety toward maths between } \\
\text { male and female students } \\
(U=2270.5, p=0.541) \\
\text { No significant differences in } \\
\text { self-efficacy between male and } \\
\text { female students }(U=2110.5, \\
p=0.198)\end{array}$ & Gender \\
\hline Paechter et al. [21] & Austria & Psychology & $\begin{array}{l}\text { Prospective cohort } \\
n=225\end{array}$ & $\begin{array}{l}\text { High maths anxious individuals } \\
\text { have less precise representa- } \\
\text { tions of numerical magnitude } \\
\text { than their low maths anxious } \\
\text { peers } \\
\text { Female students report higher } \\
\text { levels of maths anxiety } \\
\beta=0.660 \\
\text { Participants with a higher pro- } \\
\text { pensity to experience anxiety } \\
\text { in general report higher levels } \\
\text { of maths anxiety ( } \beta=0.385 \text { ) }\end{array}$ & Gender \\
\hline
\end{tabular}




\section{Self-awareness}

Self-awareness helps people to manage themselves and improve performances while the opposite is true that lacking self-awareness leads to making the same mistakes repeatedly [25]. Being self-aware enables us to determine our strengths and areas that can be improved [25]. Four studies addressed the self-awareness concept in relation to maths anxiety, one American study, one UK study, one Israeli study and one Portuguese study. Under the selfawareness theme, a number of other subthemes emerged including self-efficacy, maths confidence, maths value, maths barriers and performance. McMullan et al. [26] developed a Drug Calculations Self-Efficacy Scale that measured critical skills of medication calculations (dose of liquid oral drugs, solid drugs, injections, percentage solutions and infusion and drip rates). McMullan et al. [26] reported that there was a significant positive correlation between students' maths self-efficacy and maths performance and between maths self-efficacy, drug calculation self-efficacy and drug calculation performance. Low level of maths anxiety was demonstrated by $10 \%$ of the students, medium level by $70 \%$ and high level by $20 \%$ of the students. McMullan et al. [26] also noted that numerical skills can be improved by remedial approaches as lectures, study groups, workshops and computer assisted instructions [27]. The authors suggested that the lectures should be more student-directed not only didactic in nature. Study groups increase the cooperation and encourage students to exchange and clarify information leading to improve the self-efficacy.

Maths confidence, maths value and maths barriers are related to maths behaviour and performance. Hendy et al. [28] studied maths behaviours in 368 university maths students. They reported maths behaviours (attending class, doing homework, reading textbooks and asking for help) at week 8 of the 15 week-semester using self-reported questionnaires. The aim of their study was identify the subclasses of maths beliefs and their role in maths behaviours. The most commonly reported maths belief was maths confidence (mean rating $=3.79, \mathrm{SD}=0.90)$. This study reported that students with low maths confidence or high maths anxiety might benefit from the maths self-evaluation and self-regulation interventions. These interventions utilised suggestions which include: maths skills are learnable not innate, assessing current skills and believing in their development abilities, teaching student the specific strategies to solve maths problems and keeping self-regulatory records to track development in overcoming maths anxiety. These interventions may be used in overcoming maths anxiety. This study outlined the approach to develop interventional teaching methods that can be applied to students or course curriculum to help in reducing maths anxiety. Self-awareness might determine the person's areas of strength that might help future career selection. Self-efficacy, maths confidence and values, maths barriers and performance are factors that related to self-awareness. Assessing these factors can determine the methods of improving selfawareness which may end in overcoming maths anxiety.

\section{Numerical ability}

Two articles addressed the numerical ability concept $[25,2]$. In their efforts to understand the origin of maths anxiety, Maloney et al. [29] investigated the processing of symbolic magnitude by high and low maths anxious individuals. They reported that high maths anxious individuals have less precise representations of numerical magnitude than their low maths anxious peers. Two experiments were performed on 48 undergraduate students in the University of Waterloo. A single Arabic digit in 18-font Arial font was presented at fixation. Numbers ranged from $1-4$ to from 6-9. The participants were told to identify whether the number above five or below it. This study revealed that high maths anxious individuals have a less precise representation of numerical magnitude than the low maths anxious individuals. The results suggest that maths anxiety is associated with low level numerical deficits that compromise the development of higher level mathematical skills.

On the other hand, McMullan et al. [26] reported that numerical ability and maths anxiety are the main personal factors that might influence drug calculation ability in nursing students. The numerical ability test (NAT), used by McMullan et al. [26], is comprised of 15 questions that covered calculation operations like multiplication, addition, fraction, subtraction, percentage, decimals and conversion. McMullan et al. [26] reported that both numerical ability and drug calculation abilities of the participants (229 UK nursing students) were poor which might have been to an over-reliance on using calculators or not having adequate maths education in the past. Improving numerical ability and reducing maths anxiety can be achieved through teaching in a supportive environment using multiple teaching strategies that address the needs of all students and not being didactic [26]. Examples of these strategies include: accept and encourage students creative thinking, tolerate dissent, encourage students to trust their judgments, emphasise that everyone is capable of creativity, and serve as a stimulus for creative thinking through brainstorming and modelling [30]. 


\section{Learning difficulty}

Australian surveys have indicated that 10 to 16 per cent of students are perceived by their teachers to have learning difficulties according to Learning Difficulty Australia (LDA) (2012). Within the population of students with learning difficulties, there is a smaller subset of students who show persistent and long-lasting learning impairments and these are identified as students with a learning disability. It is estimated that approximately 4 per cent of Australian students have a learning disability (LDA 2012).

In this scoping review, one UK study addressed this concept, comparing undergraduate psychology students who represent $71 \%$ of the sample and nursing students who represent $14 \%$ of the sample who either had dyslexia $(n=28)$ or were assigned to the control group $(n=71)$. In 2014 Jordan et al. [31] reported that students with dyslexia had higher levels of maths anxiety relative to those without [31]. This study showed that significant correlations with maths anxiety were found for self-esteem $(r=-0.327 ; n=99, p .001)$, worrying $(r=393 ; n=99$; $p<0.001$ the denial $(r=0.238 ; n=99 ; p=0.018$, seeking instrumental support $(r=0.206 ; n=99 ; p=0.040$ and positive reinterpretation $(r=-0.216 ; n=99 ; p=0.032)$. In addition, this study found that seeking instrumental support served as an indicator of students at high risk of maths anxiety. In explaining variation in maths anxiety. Jordan et al. [31] claimed that $36 \%$ of this variation is due to dyslexia, worrying, denial, seeking instrumental support and positive reinterpretation. The limitation of this study is that not all dyslexia cases were disclosed by the students. As long as some of the students with dyslexia are not reported, the generalisation of this study would be limited. This study recommends positive reframing and thought challenging as techniques to overcome difficult emotions and anxiety.

\section{Limitations and future research}

While multiple databases were used in this scoping review, some articles may be missed due to using specific terms in the search strategy. The disciplines covered in this scoping review were psychology, engineering, mathematics and some of the health disciplines such as nursing. Future research might focus on numerical ability and maths anxiety in university students who need maths and calculation in their future careers as engineers and health care professionals.

For example, the relationship between medication and drug calculation errors and maths anxiety in the health care field can be researched. Moreover, the relationship between self-awareness and numerical ability and maths anxiety and their impact on the performance and ability of the university students can be a future research topic.
Finally, developing a new teaching package or strategy that reduces maths anxiety can be tested on university students.

\section{Conclusion}

Maths anxiety,which is an issue that affects many disciplines across multiple countries and sectors, is affected by gender, self-awareness, learning difficulties and numerical ability. Maths anxiety and its contributing factors at tertiary education should be researched more in the future addressing interventions and strategies to overcome maths anxiety. Maths anxiety level measuring tools should be used in determining its level among university students.

\section{Abbreviations}

CINHAL: Cumulative Index of Nursing and Allied Health Literature; ERIC: Education Resources Information Centre; HMA: High Maths Anxious; LDA: Learning Difficulty Australia; LMA: Low Maths Anxious; MBS: Maths Barrier Scale; MCS: Maths Confidence Scale; MeSH: Medical Subject Headings; MVS: Maths Value Scale; UK: United Kingdom; US: United States; R-MARS: Revised Maths Anxiety Rating Scale.

\section{Acknowledgements}

We would like to acknowledge Monash University librarians for their help and support.

\section{Authors' contributions}

EK conceived, designed and carried out the study, interpreted the analysis, and drafted and revised the manuscript. BW conceived, designed, drafted and revised the manuscript. CG helped conceive, drafted and revised the manuscript. All authors read and approved the final manuscript.

\section{Funding}

Not applicable.

Availability of data and materials

It is a scoping review and all the articles that are analysed in this review are listed in the references section.

Ethics approval and consent to participate Not applicable.

\section{Competing interests}

The authors declare that they have no competing interests.

\section{Author details}

${ }^{1}$ Department of Community Emergency Health and Paramedic Practice, Monash University, Monash University-Peninsula Campus, McMahons Road, Frankston, VIC, Australia. ${ }^{2}$ Faculty of Applied Medical Sciences, Jordan University of Science and Technology, Irbid, Jordan.

Received: 14 July 2019 Accepted: 15 October 2020

Published online: 25 February 2021

\section{References}

1. Ashcraft MH. Math anxiety: personal, educational, and cognitive consequences. Curr Dir Psychol Sci. 2002;11(5):181-5.

2. Olango M. Mathematics anxiety factors as predictors of mathematics self-efficacy and achievement among freshmen science and engineering students. Afr Educ Res J. 2016:4(3):109-23. 
3. Mammarella IC, Hill F, Devine A, Caviola S, Szucs D. Math anxiety and developmental dyscalculia: a study on working memory processes. J Clin Exp Neuropsychol. 2015;37(8):878-87.

4. Helal A, Abo Hamza E, Hagstorm F. Math anxiety in college students across majors: a cross culture study. 2011.

5. Harari RR, Vukovic RK, Bailey SP. Mathematics anxiety in young children: an exploratory study. J Exp Educ. 2013;81:538-55.

6. Røykenes K, Larsen T. The relationship between nursing students' mathematics ability and their performance in a drug calculation test. Nurse Educ Today. 2010;30:697-701.

7. Mutodi P, Ngirande H. Exploring mathematics anxiety: mathematics students' experiences. Mediterr J Soc Sci. 2014;5(1):283-94.

8. McNaught M, Grouws D. Learning goals and effective mathematics teaching: What can we learn from research? Taiwan J Math Teach. 2007;10:2-11.

9. Maloney EA, Ramirez G, Gunderson EA, Levine SC, Beilock SL. Intergenerational effects of parents' math anxiety on children's math achievement and anxiety. Psychol Sci. 2015;26(9):1480-8.

10. Eispino M, Pereda J, Recon J, Perculeza E, Umali C. Mathematics anxiety and its impact on the course and career choice of grade 11 students. Int J Educ Psychol Couns. 2017;2(5):99-119.

11. Uusimaki L, Kidman G. KID04997 Reducing maths-anxiety: results from an online anxiety survey. 2004.

12. Taylor JA, Mohr J. Mathematics for math anxious students studying at a distance. J Dev Educ. 2001;25:30-8.

13. Marshall E, Mann V, Wilson D. Teaching strategies for helping students overcome maths anxiety. 2016.

14. Dreger $R$, Alken $L$. The identification of number anxiety in a college population. J Educ Psychol. 1957:48:344-51.

15. Arksey H, O'Malley L. Scoping studies: towards a methodological framework. Int J Soc Res Methodo. 2005:8:19-32.

16. Levac D, Colquhoun H, O'Brien KK. Scoping studies: advancing the methodology. Implement Sci. 2010;5(59):1-9.

17. Kirkevold M. Integrative nursing research-an important strategy to further the development of nursing science and Practice. J Adv Nurs. 1997;25:977-84

18. Liew J, Lench HC, Kao G, Yeh YC, Kwok OM. Avoidance temperament and social-evaluative threat in college students' math performance: a mediation model of math and test anxiety. Anxiety Stress Coping. 2014;27(6):650-61.
19. Hopko DR, McNeil DW, Lejuez CW, Ashcraft MH, Eifert GH, Riel J. The effects of anxious responding on mental arithmetic and lexical decision task performance. J Anxiety Disord. 2003;17(6):647-65.

20. Hunt TE, Clark-Carter D, Sheffield D. Exploring the relationship between mathematics anxiety and performance: an eye-tracking approach. Appl Cogn Psychol. 2015;29(2):226-31.

21. Paechter M, Macher D, Martskvishvili K, Wimmer S, Papousek I. Mathematics anxiety and statistics anxiety. Shared but also unshared components and antagonistic contributions to performance in statistics. Front Psychol. 2017:8:1196.

22. Zeidner M. Statistics and mathematics anxiety in social science students: some intersting parallels. Br J Educ Psychol. 1991;61:319-28.

23. Alves M, Rodrigues CS, Rocha AMAC, Coutinho C. Self-efficacy, mathematics' anxiety and perceived importance: an empirical study with Portuguese engineering students. Eur J Eng Educ. 2015;41(1):105-21.

24. Devine A, Fawcett K, Szucs D, Dowker A. Gender differences in mathematics anxiety and the relation to mathematics performance while controlling for test anxiety. Behav Brain Func. 2012;8:33.

25. Rasheed S. Self-awareness as a therapeutic tool for nurse/client relationship. Int J Caring Sci. 2015;8(1)

26. McMullan M, Jones R, Lea S. Math anxiety, self-efficacy, and ability in British undergraduate nursing students. Res Nurs Health. 2012;35(2):178-86.

27. Jukes L, Gilchrist M. Concerns about numeracy skills of nursing students. Nurse Educ Pract. 2006;6(4):192-8.

28. Hendy HM, Schorschinsky N, Wade B. Measurement of math beliefs and their associations with math behaviors in college students. Psychol Assess. 2014;26(4):1225-34.

29. Maloney EA, Ansari D, Fugelsang JA. The effect of mathematics anxiety on the processing of numerical magnitude. Q J Exp Psychol. 2011;64(1):10-6.

30. Cole DG, Sugioka HL, Yamagata-Lynch LC. Supportive classroom environments for creativity in higher education. J Creat Behav. 2011:33:277-93.

31. Jordan JA, McGladdery G, Dyer K. Dyslexia in higher education: implications for maths anxiety, statistics anxiety and psychological well-being. Dyslexia. 2014;20(3):225-40.

\section{Publisher's Note}

Springer Nature remains neutral with regard to jurisdictional claims in published maps and institutional affiliations.
Ready to submit your research? Choose BMC and benefit from:

- fast, convenient online submission

- thorough peer review by experienced researchers in your field

- rapid publication on acceptance

- support for research data, including large and complex data types

- gold Open Access which fosters wider collaboration and increased citations

- maximum visibility for your research: over $100 \mathrm{M}$ website views per year

At $\mathrm{BMC}$, research is always in progress.

Learn more biomedcentral.com/submissions 